\title{
Role of Computers in Reading Skills
}

\author{
Dr. Anjali Hans, Mr. Emmanuel Hans \\ (Lecturer in English-University of Dammam Kingdom of Saudi Arabia)
}

\begin{abstract}
Reading is a complex cognitive process of decoding symbols in order to construct or derive meaning (reading comprehension). It is a means of language acquisition, of communication, and of sharing information and ideas. Like all language, it is a complex interaction between the text and the reader which is shaped by the reader's prior knowledge, experiences, attitude, and language community which is culturally and socially situated. The reading process requires continuous practice, development, and refinement. Reading skills refer to the specific abilities that enable a person to read with independence and interact with the message. Students at the university do a lot of reading unlike in secondary school. Some tips to help in having good reading skills are active reading and styles of reading. This study examines the role of computers having advantages like Computer software is interactive, Computer software uses scientificallyassisted educational research, Computer software creates a "real" learning development, The interactive potential of Computer Assisted Learning, Power, Versatility. It has some disadvantages like effective demands, logistics and Methodological Limitations.
\end{abstract}

Key Words: Reading, Language, Computers, Reading Skills

\section{Introduction}

Computers are being used increasingly in educational contexts, little research on using computers in reading instruction exists. Nuttal (2005) states that "the aims of reading program are to enable students to enjoy (or at least feel comfortable with) reading in the foreign language, and to read without help unfamiliar texts, at appropriate speed, silently and with adequate understanding." The students are able to enjoy reading some texts if they understood well, so it needs more comprehension, as the comprehension means the capability to give details about grammar and structure of a page of text, it also means the ability to sum up the thesis and argument of a whole book in a few sentences (Ann and Lee, 1997). According to the aims of reading, the teachers use many methods to teach as they do their effort to make the students enjoy reading the text and achieve the purposes; moreover they use the computers to assist language learning. This paper discusses what reasons do the teachers use computers to develop reading skills; is it possible to use computers? Is it sensible or appropriate to use computers for such purposes?

\section{WHAT IS READING?}

Teachers have some methods to teach English as second language, to make the students are able to speak fluently and write well, and also comprehend the text. Those are named by "language skills" (listening, reading, speaking and writing). Reading is a part of language skills. Brynes (1998, 2 ) states "Reading is an interactive process that goes on between the reader and the text, resulting in comprehension. The text presents letters, sentences, and paragraphs that encode the meaning."

According to Brynes' definition, reading can be either language skill or process which determines the reader to use knowledge, skills and strategies. Reader knowledge, skills and strategies include:

1. Linguistic competence as the ability to recognize the elements of the writing system; understanding of vocabulary: comprehension of how words are structured into sentences.

2. Discourse competence it is the knowledge of discourse markers and how they fix parts of the text to one another.

3. Sociolinguistic competence as knowledge about different type of texts and their usual structure and content.

4. Strategic competence it is the ability to use top down strategies as well as knowledge of the language (Bryners 1998, 2).

Moreover, reading and the type of text have the purpose to determine the specific knowledge, skills and strategies that the reader need to apply to achieve reading comprehension. Because reading comprehension is more than decoding, it results when the reader knows which skill and strategies are suitable for the type of text, and understands how to relate them to complete the purpose (Bryners 1998). Reading is an essential part of language instruction at every level because it supports learning in multiple ways.

- Reading to learn the language: Reading material is language input. By giving students a variety of materials to read, instructors provide multiple opportunities for students to absorb vocabulary, grammar, sentence 
structure, and discourse structure as they occur in authentic contexts. Students thus gain a more complete picture of the ways in which the elements of the language work together to convey meaning.

- Reading for content information: Students' purpose for reading in their native language is often to obtain information about a subject they are studying, and this purpose can be useful in the language learning classroom as well. Reading for content information in the language classroom gives students both authentic reading material and an authentic purpose for reading.

- Reading for cultural knowledge and awareness: Reading everyday materials that are designed for native speakers can give students insight into the lifestyles and worldviews of the people whose language they are studying. When students have access to newspapers, magazines, and Web sites, they are exposed to culture in all its variety, and monolithic cultural stereotypes begin to break down.

\section{Reading skills}

Many people have trouble with reading. Reading is hard for some people and it can take time. Reading is a process of the brain where you look at symbols on a page, and your mind sees the patterns of characters and understands the meaning in them. If you develop good reading skills, it'll be very helpful to your future. Aren't your school teachers always saying 'Read more books!'? Here are a few steps and tips to get started.

\section{Steps}

1. Find something to read. Examples include a children's book, a newspaper article, a short story, or something on wikiHow.Sound out each letter as best you can and you will notice they form some sort of word. Some letters fit together. For example, "th" is not pronounced as $t+h$, but rather as one unit. This is called a 'phoneme'

2. Find a place to read where you can concentrate. This may be someplace secret where no one will bother you, or simply your home at a time when it is quiet.

3. Begin your reading by looking at the pictures, or listening to the music to get a feel for what you are going to be reading about.

4. Start with titles, names, or other larger print items that you may know or ever thought about.

5. Read as much as you are able. When you start getting bored or need a break, take one.

6. Reading should be fun and enjoyable, don't force it. After your break, return to where you were, and continue.

7. Reread the material. It is okay to reread something if you do not understand it fully the first time.

8. Go to the library and pick up lots of books. Pick books depending on your readinglevel, no matter what your age.

9. Read the page carefully. Don't rush, take your time. Most people think that skimming the page(skimming means to just scan the whole page and hardly take in a couple of words)is a way of fast reading, but this is definitely not true.

10.Use context clues to find out a word's meaning. Context clues are when a person figures out the meaning of a word by seeing how the word was used in a sentence. For example, you were reading the following sentence and wanted to know what 'pessimist' means:My mother is always happy and optimistic, the total opposite of my brother, the pessimist. So from the sentence, you can gather that 'pessimist' means the opposite of happy, so pessimist means being moody and angry. Good, experienced readers always use context clues! If you find a word that you're totally stumped on, use the dictionary! If you want to save time and the hassle of turning pages, go to the online dictionary

\section{Effective language instructors}

Effective language instructors helps the students that how they can adjust their reading behavior to deal with a variety of situations, types of input, and reading purposes. They help students develop a set of reading strategies and match appropriate strategies to each reading situation. When language learners use reading strategies, they find that they can control the reading experience, and they gain confidence in their ability to read the language.

Strategies that can help students read more quickly and effectively include

- Previewing: reviewing titles, section headings, and photo captions to get a sense of the structure and content of a reading selection

- Predicting: using knowledge of the subject matter to make predictions about content and vocabulary and check comprehension; using knowledge of the text type and purpose to make predictions about discourse structure; using knowledge about the author to make predictions about writing style, vocabulary, and content

- Skimming and scanning: using a quick survey of the text to get the main idea, identify text structure, confirm or question predictions 
- Guessing from context: using prior knowledge of the subject and the ideas in the text as clues to the meanings of unknown words, instead of stopping to look them up

- Paraphrasing: stopping at the end of a section to check comprehension by restating the information and ideas in the text

Instructors can help students learn when and how to use reading strategies in several ways.

- By modeling the strategies aloud, talking through the processes of previewing, predicting, skimming and scanning, and paraphrasing. This shows students how the strategies work and how much they can know about a text before they begin to read word by word.

- By allowing time in class for group and individual previewing and predicting activities as preparation for in-class or out-of-class reading. Allocating class time to these activities indicates their importance and value.

- By using cloze (fill in the blank) exercises to review vocabulary items. This helps students learn to guess meaning from context.

- By encouraging students to talk about what strategies they think will help them approach a reading assignment, and then talking after reading about what strategies they actually used. This helps students develop flexibility in their choice of strategies.

\section{Uses Of Computers In Reading Instruction}

Technological advances continue to expand possibilities for using computers to support reading instruction. An important application is in direct instruction of basic skills. Computers offer engaging, interactive activities for general and targeted practice. They give student immediate corrective feedback, and some programs provide incentives for progress to higher levels of difficulty. Teachers also use programs to track student progress.

Computers allow students to create and share work. Some software allows them to create graphics and multimedia projects, while word processing facilitates writing projects. The internet allows information sharing through such resources such online research, personal web pages, and e-mail. Moreover, electronic references allow students to conduct research more easily and in new and different ways from traditional research.

One of the biggest concerns of teachers and instructors is that students are failing to learn critical reading skills that they need to progress satisfactory through the upper levels of their education. Commercial reading software developers have worked hard to create software that gives learners real opportunities to read critically and develop critical reading, and critical thinking, skills. Research is just beginning to clarify the cognitive and effective consequences of using computers to teach literacy. Investigations have shown that computer tools can enhance instruction. The use of word processors can produce better writing. Multimedia presentations can facilitate comprehension. Computers benefits diverse Learner by allowing for individualized instruction. Computerized vocabulary tools enhance second language learners' comprehension, and computer-assisted instruction teaches basic reading skills to students at risk. Moreover, studies have found effects on engagement and interest, particularly for students with learning difficulties. And the advantages are:

\section{Computer software is interactive.}

The most important benefits of commercial reading software is its ability to engage the students. Most current reading requires that a student do more than merely punch buttons. The interactive software provides students with the chance to produce their own questions and leads the students through guided practice situations. Newer software has even developed ways for students to interact with each other via the internet. Students work together in virtual groups to expand the learning experience.

\section{Computer software uses scientifically-assisted educational research.}

The reality is that educational software that purports to teach without the assistance of sound research and statistics often fails to hit the mark when it comes to really educating children. It is important to use software based on established teaching strategies as well as credible research studies.

\section{Computer software creates a "real" learning development.}

Until the advent of desktop computers, reading experiences were limited ti print materials. Early programs were only used as supplements to a general reading lesson, rather than acting as a stand-alone reading experience. These factors meant that early computer reading programs could not meet the needs of children learning to read critically.

\section{Interaction \\ 4.1.Man-machine interaction.}


The interactive potential of CAL( COMPUTER ASSISTED LEARNING) has been extolled for the last twentyfive years or more. For example, Rigney $(1962,156)$ writes: "It is ... an interactive notion that a computer can be programmed to interact dynamically with one or more students."

\subsection{Interpersonal interaction}

In Talking about 'interaction', Rigney and his contemporaries were thinking in terms of communication between man and machine, and it has been largely in these terms that CAL has developed. In language acquisition, however, most interaction is between people. The very purpose of first language acquisition is to make interaction possible (Wells 1981, 16). Interaction is the goal and language the means. The central role of interaction in language acquisition has been emphasized in recent research (e.g. Ellis 1984), and in the whole tradition of communicative teaching. The use of computers within interactive settings as an element in a group practice is well established.

\subsection{Reader - text interaction}

Another form of interaction which is particularly important in the context of reading is between reader and text (Widdowson 1979, 173). In this approach, the computer can be conceived of as an aid, supplementing the printed page or other teaching material, and not providing the total learning environment. This approach would see it as the teacher's task to create the learning environment, using the computer as an element within it just as she might use integrated skills practice or an overhead projector.

Thus computers can play a variety of interactive roles. They can promote interaction of various sorts-between man and machine (which is generally absorbing and motivating), between people (which is likely to promote language acquisition), and between reader and text (where the computer often plays a supportive role).

\section{Power}

The calculating power of computer is legendary, together with their capacity to search speedily through databases or print text up on the screen. In reality, however, the microcomputers generally used for CAL work are essentially toy instruments, sometimes even derided by computers scientists with their considerably more powerful mainframe computers.

There are some programs that allow the teacher to specify several possible 'correct responses', but it is often impossible for her to anticipate all the zany responses that may come up. Other words, computers can actually be constraining and limiting. It is not enough simply to blame the software, for the problem also derives from the limited power of the machine and the near impossibility of anticipating all possible responses.

Indeed, work with computers tends to make one realize how flexible and cognitively powerful human teachers are. Thus computers can be described as powerful but only within certain restricted domains. For the reader these include text manipulation exercises, lexical and technical databases, speed reading exercises and simulation.

\section{Versatility}

Despite any limitations of memory or processing power, computers are surprisingly adaptable and versatile devices. All the vocabulary recognition strategies described by Williams (1985) could be practiced with CAL programs. Some approaches use computers not so much to provide CAL exercises as to serve as facilitator (Sharples 1985), providing the learner with a toolkit to help learning process to place.

It is clear that computer, in the way they are at present used to reading skills, are very useful in certain areas, but nevertheless essentially limited. To promote the computer as capable of providing the complete learning environment is therefore unrealistic. To recommend its use as an element in an overall learning environment, on the other hand, seems a more practicable approach.

\section{Effective Demands}

\section{The Disadvantages Of Using Computers To Develop Reading Skills}

The effective demands of working with computers vary with the user. Young learners, on the whole, experience little difficulty. It is generally older users, such as teachers, who may experience feeling inadequacy or even of hostility to the machines. These attitudes are probably fairly common, and may help to explain the slow spread of CAL.

\section{Logistics}

\subsection{Access}

At the practical level, the biggest difficulty associated with using CAL in reading training or for other language work is getting enough computers. In most institutions using CAL, one machine per classroom (or more) is the rule. Student access to the machine is generally limited in time and shared with other people. (In fact, students can work at computers in pairs without loss of effectiveness). 


\subsection{Materials}

While a certain amount of software is available, particularly for the BBC and Apple computers, the high costs of programming and the small sales compared with books mean that only limited amount of software is published ( Rope 1985,67). Furthermore, programs written for BBC computer, say, will not work on an Apple or an IBM. Translation programs do exist, but they only work under certain conditions.

\subsection{Computer Screens.}

It has been argued that the computer screen can be used in versatile ways. However it doesn't look like paper, and presumably reading training should be primarily directed towards reading texts on the paper. When one finishes a page in a book, for example, one turns over to the next page. The computer on the other hand, usually scrolls, so the text you have been reading moves up to the top of the screen and disappears, while the new section of text moves up into the view from the bottom. It is much easier to find something by thumbing back through a book than by scrolling back a computer screen.

\section{Methodological Limitations.}

Some of the methodological limitations of CAL have been discussed already, such as the problems of dealing with unanticipated responses. Another restriction is that the computer cannot understand speech, so that most CAL practice at the keyboard is confined to reading and writing.

More insidious has been the impact of the computer on CAL methodology. Right from the beginnings of CAL around 1960 to the present, most CAL exercises have been drills, and in majority of them meaning secondary. Although applied linguistics and Cognitive Psychology have doubted the wisdom of using meaningless drill as a primary way of learning languages, such drill is still common in CAL practice, legitimated by the technology.

\section{Conclusion}

To summarize the argument of this paper: computers are powerful and versatile devices, but they do have a number of disadvantages, carry no guarantee of success, and need to be used with care. Introducing CAL doesn't make the task of EFL teachers easier, for successful integration of the computer into the learning program demands ingenuity and effort. Programs exist for the development of reading strategies, for example, and to develop inference skills in assigning meaning to unknown words. More tool software will become available, giving readers access to dictionaries, lexicons etc. Integrated reading and writing work round projects, using word-processors and attendant spelling checkers etc, looks a promising area for development.

Computers are known to be motivating for students. To get the best results with them, teachers will need both enthusiasm and discernment.

\section{References}

[1]. Kim,S, Helen and Kamil, L, Michael. 2005. Successful uses of computer technology for reading instruction.http://www.temple.edu/lss/LivingDocuments/PDF/kimkamil_summary.pdf. (Accessed 18 Feb,2010).

[2]. Ingram ,Fiona.2010.Three reasons to use computers to teach critical reading skills.http://hubpages.com/hub/Three-Reasons-to-UseComputers-to-Teach-Critical-Reading-Skills.

[3]. Aebersold, Jo Ann and Fied, Mary Lee. 1997. From reader to reading teaching: Issues and strategies for second language classroom.Ed, Richard, Jack C. Melbourne. Cambridge University.

[4]. Nuttal, Christine. 2005. Teaching reading skills in a foreign language. Thailand. Mc. Millan Publisher.

[5]. Ellis, R. 1984. Classroom second language development. Oxford. Pergamon. 